\title{
Performance analysis of a Kalina cycle for a central receiver solar thermal power plant with direct steam generation
}

\section{Modi, Anish; Haglind, Fredrik}

\section{Published in:}

Applied Thermal Engineering

Link to article, DOI:

10.1016/j.applthermaleng.2014.01.010

Publication date:

2014

Link back to DTU Orbit

Citation (APA):

Modi, A., \& Haglind, F. (2014). Performance analysis of a Kalina cycle for a central receiver solar thermal power plant with direct steam generation. Applied Thermal Engineering, 65(1-2), 201-208.

https://doi.org/10.1016/j.applthermaleng.2014.01.010

\section{General rights}

Copyright and moral rights for the publications made accessible in the public portal are retained by the authors and/or other copyright owners and it is a condition of accessing publications that users recognise and abide by the legal requirements associated with these rights.

- Users may download and print one copy of any publication from the public portal for the purpose of private study or research.

- You may not further distribute the material or use it for any profit-making activity or commercial gain

- You may freely distribute the URL identifying the publication in the public portal 


\author{
Performance analysis of a Kalina cycle for a central receiver solar thermal power plant with direct steam \\ generation \\ Anish Modi ${ }^{1}$, Fredrik Haglind \\ Department of Mechanical Engineering, Technical University of Denmark, Nils Koppels Allé, Building 403, DK-2800 Kgs. \\ Lyngby, Denmark
}

\begin{abstract}
Solar thermal power plants have attracted increasing interest in the past few years - with respect to both the design of the various plant components, and extending the operation hours by employing different types of storage systems. One approach to improve the overall plant efficiency is to use direct steam generation with water/steam as both the heat transfer fluid in the solar receivers, and the cycle working fluid. This enables operating the plant with higher turbine inlet temperatures. Available literature suggests that it is feasible to use ammonia-water mixtures at high temperatures without corroding the equipment by using suitable additives with the mixture. The purpose of the study reported here was to investigate if there is any benefit of using Kalina cycle for a direct steam generation, central receiver solar thermal power plant with high live steam temperature $\left(450^{\circ} \mathrm{C}\right)$ and pressure (over $100 \mathrm{bar}$ ). Thermodynamic performance of the Kalina cycle in terms of the plant exergy efficiency was evaluated, and compared with a simple Rankine cycle. The rates of exergy destruction for the different components in the two cycles were also calculated and compared. The results suggest that the simple Rankine cycle exhibits better performance than the Kalina cycle when the heat input is only from the solar receiver. However, when using a two-tank molten-salt storage system as the primary source of heat input, the Kalina cycle showed an advantage over the simple Rankine cycle because of about $33 \%$ reduction in the storage requirement. The solar receiver showed the highest rate of exergy destruction for both the cycles. The rates of exergy destruction in other components of the cycles were found to be highly dependent on the amount of recuperation, and the ammonia mass fraction and pressure at the turbine inlet.
\end{abstract}

Keywords: Solar thermal power plant; direct steam generation; Kalina cycle; exergy analysis

\title{
Highlights
}

- Kalina cycle for a central receiver solar thermal power plant with direct steam generation

- Rankine cycle shows better plant exergy efficiency when heat input is only from the solar receiver

- Kalina cycle is advantageous when heat input is primarily from a two-tank molten-salt storage

\section{Introduction}

In recent times, solar thermal power plants (STPPs) have attracted interest as a large scale, commercially viable way to generate electricity [1]. In an STPP, the heat transfer fluid (HTF) and the working fluid play an important role as the carriers of energy from the collector/receiver to the turbine. This is commonly done in two stages for a plant operating with a Rankine cycle. The HTF (e.g. synthetic oil, molten salt, etc.) first collects the energy from the incident solar radiation. This energy is then passed on to the working fluid (water/steam) which carries it to the steam turbine. The main disadvantage of such two-fluid systems is that the maximum operating temperature of the HTF is limited by the fluid stability concerns (e.g. approximately $400{ }^{\circ} \mathrm{C}$ for the synthetic oil), thus resulting in a low turbine inlet temperature and consequently a low cycle efficiency.

Application of direct steam generation (DSG) in STPPs presents the prospect of improving the overall plant efficiency, while simultaneously decreasing the cost of electricity generation [2]. The pressurized steam is generated directly in the receiver and transported to the steam turbine. The advantages of DSG include a higher live steam temperature and the use of one fluid as both the HTF and the working fluid, possibly resulting in a

\footnotetext{
${ }^{1}$ Corresponding author: anmod@mek.dtu.dk; +45-45251910
} 
simplified operation. The main disadvantage of using DSG for STPPs is that it requires a very complex storage system for uninterrupted plant operation [3]. The motivation behind the current study is that the exergy losses during a heat transfer process can be reduced by using a suitable multi-component working fluid which can evaporate or condense at a varying temperature, contrary to the constant evaporating or condensing temperature for a pure substance [4]. One such multi-component working fluid is the ammonia-water zeotropic mixture, as used in a Kalina cycle (KC). There have been discussions regarding the feasibility of using ammonia-water mixtures at high temperatures due to the nitridation effect resulting in corrosion of the equipment. However, the use of an ammonia-water mixture as the working fluid at high temperature has been successfully demonstrated in Canoga Park with turbine inlet conditions of $515^{\circ} \mathrm{C}$ and 110 bar [5]. Moreover, a patent by Kalina [6] claims the stability of ammonia-water mixtures along with prevention of nitridation for plant operation preferably up to $2000^{\circ} \mathrm{F}\left(1093^{\circ} \mathrm{C}\right)$ for temperature and 10000 psia (689.5 bar) for pressure using suitable additives. It should be noted that the term direct steam generation is used here for both water and ammonia-water mixtures.

There were proposals to incorporate the KC for waste heat recovery plants, geothermal power plants or solar energy driven power plants. Such plants operate with low or medium range temperatures at the turbine inlet. Bombarda et al. [7] presented a thermodynamic comparison between the KC and an organic Rankine cycle (ORC) for heat recovery from diesel engines. They concluded that although the obtained electrical power outputs are nearly equal, the $\mathrm{KC}$ requires a much higher turbine inlet pressure to attain the same, thereby making it unjustified for such use. Singh and Kaushik [8] presented energy and exergy analysis and optimisation of a KC coupled with a coal-fired steam power plant for exhaust heat recovery. They found out that at a turbine inlet pressure of $40 \mathrm{bar}$, an ammonia mass fraction of 0.8 gives the maximum cycle efficiency and the highest exergy destruction occurs in the evaporator. Campos Rodríguez et al. [9] presented an exergetic and economic comparison between a KC and an ORC for a low temperature geothermal power plant. They found that the KC produces $18 \%$ more power than the ORC with $37 \%$ less mass flow rate. In addition, the KC had $17.8 \%$ lower levelized electricity costs than the ORC. Wang et al. [10] presented a parametric analysis and optimisation of a KC driven by solar energy. They found that the net power output and the system efficiency are less sensitive to the turbine inlet temperature under given conditions and that there exists an optimal turbine inlet pressure which results in maximum net power output. Coskun et al. [11] presented a comparison between different power cycles for a medium temperature geothermal resource. They found that the KC and the double flash cycle provided the least levelized cost of electricity and hence the lowest payback periods.

With regards to using the KC with high turbine inlet temperatures, Ibrahim and Kovach [12] studied the effect of varying the ammonia mass fraction and the separator temperature on the cycle efficiency for a Kalina bottoming cycle using gas turbine exhaust as the heat source. The KC turbine inlet conditions were $482{ }^{\circ} \mathrm{C}$ and 59.6 bar. The authors found that the KC is $10-20 \%$ more efficient than the Rankine cycle with the same boundary conditions. Nag and Gupta [13] performed an exergy analysis of a KC with gas turbine exhaust as the heat source for with a turbine inlet temperature between $475{ }^{\circ} \mathrm{C}$ and $525^{\circ} \mathrm{C}$, and a turbine inlet pressure of 100 bar. They concluded that the important parameters affecting the cycle efficiency are the turbine inlet temperature, composition and the separator temperature. Dejfors et al. [14] presented an analysis of using ammonia-water power cycles for direct fired cogeneration plants with a maximum temperature of $540{ }^{\circ} \mathrm{C}$. They concluded that for a cogeneration configuration, the Rankine cycle performs better than the KC whereas for the conventional condensing power application, the performance of the KC is better. Knudsen et al. [15] presented the results from the simulation and exergy analysis of a KC for an STPP having a turbine inlet temperature of $550{ }^{\circ} \mathrm{C}$ when the heat input is from a solar receiver, and $480^{\circ} \mathrm{C}$ when the heat input is from a molten-salt storage system. The authors varied the heat input to the cycle so as to maintain the turbine inlet conditions while assuming the same mass flow rate for all the cases. Modi et al. [16] presented a comparison between a Rankine cycle and an ammonia-water cycle for STPPs with a turbine inlet temperature of $450{ }^{\circ} \mathrm{C}$. The cycle energy efficiency and the storage size requirement were used as the comparison parameters. With regards to the analysis of central receiver STPPs, Xu et al. [17] presented the energy and exergy analysis of a central receiver STPP operating with a Rankine cycle. They concluded that the efficiency of the plant can be increased by focussing on reducing the losses in the receiver and by using advanced power cycles. 
A recent review of research on the KC by Zhang et al. [18] highlights the use of KC for various applications like bottoming cycle, low temperature geothermal, industrial waste, etc. In the review [18], and to the authors' knowledge, there were no studies using the KC for high temperature STPPs with DSG. The purposes of the current study are to assess the potential benefits of using a KC for a central receiver STPP with DSG using exergy analysis, analyse the trend of the rate of exergy destruction in different components of the plant with respect to the pressure and the ammonia mass fraction at the turbine inlet, and compare the performance with a simple Rankine cycle (SRC). To attain these objectives, the KC was modelled and optimised for maximum work output for the assumed boundary conditions, and analysed for operation when the heat input was only from the solar receiver, or when the primary source of heat input was a two-tank molten-salt storage system. The ammonia mass fraction is defined here as the mass of ammonia in the ammonia-water mixture to the total mass of the mixture. The paper is structured as follows: Section 2 presents the assumptions and the modelling procedure, Section 3 presents the results from the exergy analysis and the operation from molten-salt storage system, Section 4 discusses the results and Section 5 concludes the paper.

\section{Methodology}

The layouts of the compared cycles while receiving heat input solely from solar radiation are presented in Figure 1 (SRC) and Figure 2 (KC). With reference to Figure 1, the superheated steam obtained from the receiver (stream 1) is expanded in the turbine. The low temperature, low pressure steam (stream 2) is then condensed to obtain saturated liquid (stream 3) which is then pumped till the turbine inlet pressure is attained (stream 4).



Figure 1: Schematic for the simple Rankine cycle (SRC)

Several cycle layouts have been proposed for power plants operating with a KC with input from different types of heat sources [18]. In this study, the layout was kept in a simple form with one separator and two recuperators as it was compared with the most basic Rankine cycle. 


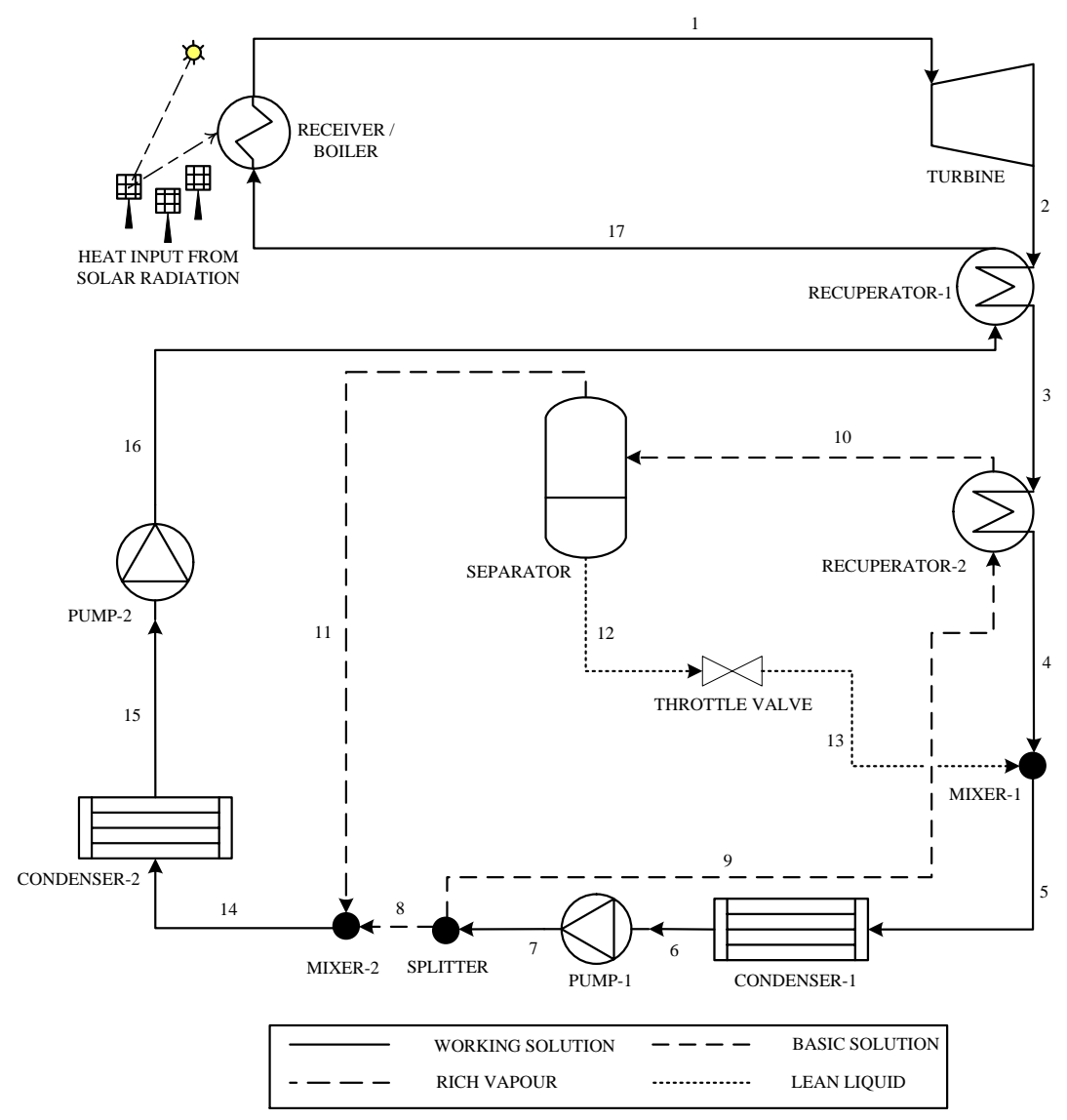

Figure 2: Schematic for the Kalina cycle (KC)

With reference to Figure 2, the working solution ammonia-water mixture entering the turbine (stream 1) is expanded. Energy is recovered from stream 2 to preheat the working solution in recuperator-1. In order to have a low condensation pressure in the condenser-1, a separator is used from which a rich ammonia vapour (stream 11) and a lean ammonia liquid (stream 12) are obtained. The lean liquid is mixed with the working solution (in mixer-1) and thus the ammonia mass fraction in condenser- 1 is reduced. The mass flow rate in the separator loop is determined by the satisfaction of the pinch point criterion for the recuperator-2. A throttle valve is used to bring the pressure of the lean liquid (stream 12) down to the pressure level of the working fluid (stream 4) before mixing in mixer-1. The rich vapour (stream 11) is mixed with the basic solution (stream 8) to again form the working fluid (stream 14) before going through the condenser-2 and the pump-2 to increase the pressure equal to the turbine inlet pressure. After the pump-2, the working fluid is heated up to the turbine inlet temperature in the receiver.

The analysis presented in this paper consisted of the following parts:

a. The KC and the SRC were modelled using Aspen Plus (v7.2) [19]. The thermophysical properties of the working fluids for both the cycles were evaluated using the Peng-Robinson equation of state with BostonMathias extension (PR-BM) [20]. All the models were steady-state models. For all the cases, the cycles were optimised to deliver the maximum possible work output with the same turbine inlet temperature $\left(450{ }^{\circ} \mathrm{C}\right.$ ) and the same amount of energy input. For the SRC, the simulations were performed by varying the turbine inlet pressure until the vapour fraction at the turbine outlet reaches its minimum value $(0.85)$. For the $\mathrm{KC}$, the cycles were optimised by varying the temperature difference between stream 3 and stream 10 (in Figure 2), and the temperature at the receiver inlet (stream 17 in Figure 2) while making certain that the pinch point temperature difference (PPTD) remains above the minimum values (as mentioned in the assumptions later) in all the heat exchangers. The set of values for various streams for the optimised cycles is termed as the design point of operation. 
b. An exergy analysis was then performed to determine the plant exergy efficiency (the ratio of the net work output to the exergy available in the solar radiation incident on the receiver surface), and the components where most exergy was destroyed or lost in the different cycle configurations.

c. Finally, the solar receiver was replaced by a two-tank molten-salt storage system as the primary source of heat input (Figure 3) with HITEC molten-salt [21] as the storage medium. The high temperature of the storage was fixed at $430{ }^{\circ} \mathrm{C}$ (assumed to be $20^{\circ} \mathrm{C}$ below the turbine inlet temperature since the storage was supposed to be charged by the vapour generated in the solar receiver itself). Similarly, it was also assumed that the molten-salt can only heat the working fluid up to $410{ }^{\circ} \mathrm{C}$ (again $20^{\circ} \mathrm{C}$ below the molten-salt hot temperature), and an additional external heater (e.g. a fossil fuel or biomass fired burner) is employed to heat the working fluid to $450^{\circ} \mathrm{C}$, the turbine inlet temperature, so that the power cycle always operates at the design point. The cold temperature of the storage was then calculated so as to maintain the pinch point condition for the storage heat exchanger. It was assumed that the cold temperature of the molten-salt (HITEC) cannot go below $180^{\circ} \mathrm{C}$ to avoid freezing of the salt which occurs at $142{ }^{\circ} \mathrm{C}$ [21]. The specific heat capacity of HITEC was assumed to be equal to $0.373 \mathrm{cal} /\left(\mathrm{g}{ }^{\circ} \mathrm{C}\right.$ ) [21] or $1567.1 \mathrm{~J} /(\mathrm{kg} \mathrm{K})$. The moltensalt mass flow rate required by the cycles was then evaluated for different turbine inlet pressures and ammonia mass fractions. Only the discharge cycle for the storage system was considered in the current study. This part of the analysis was modelled using MATLAB (R2013a) as Aspen Plus does not include HITEC in its component database. Also, as MATLAB has a very good interface with REFPROP [22], the thermophysical properties of the working fluid for this part of the analysis were calculated using REFPROP (v9.0).

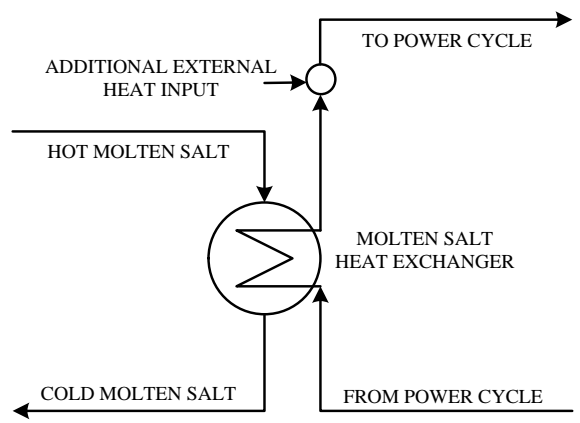

Figure 3: Two-tank molten-salt storage system with external additional heat input to operate the power cycle at design point

The following assumptions were made for the analysis:

a. Since very few central receiver STPPs with DSG are currently operative [23], and very little operational data is available in open literature regarding these plants, the solar receiver was assumed to be similar to the one used in the PS10 STPP. Similar to the PS10 plant, the receiver efficiency was assumed to be $90.2 \%$ (an annual average value, including the heat losses to the environment), and the peak design value of solar irradiance on the receiver to be $0.65 \mathrm{MW} / \mathrm{m}^{2}$ [24]. However, the area of the receiver was assumed as $42.65 \mathrm{~m}^{2}$ so that the heat input to the working fluid became $25 \mathrm{MW}$ for all the cases. It was also assumed that the irradiance is evenly distributed over the receiver area and that there were no pressure losses.

b. Pressure drops and heat losses were neglected in the other components of both the cycles.

c. The recuperators in the $\mathrm{KC}$ had a PPTD of at least $5{ }^{\circ} \mathrm{C}$. The condensers in both the cycles had a PPTD of at least $4{ }^{\circ} \mathrm{C}$. When using the molten-salt storage system instead of the solar receiver as the primary source of heat input, it was assumed to have a PPTD of at least $20^{\circ} \mathrm{C}$ in the storage heat exchanger. Since a temperature difference of $20^{\circ} \mathrm{C}$ was assumed between the hot temperature of the molten-salt and the working fluid temperature at the corresponding point in the storage heat exchanger (during both charging and discharging of the storage), a minimum PPTD of the same value was considered for the entire heat exchanger. All the heat exchangers were modelled as counter-flow heat exchangers.

d. The turbine inlet temperature was fixed at $450{ }^{\circ} \mathrm{C}$. The turbine had an isentropic efficiency of $80 \%$ and a mechanical efficiency of $98 \%$. All the pumps had an efficiency of $90 \%$. The minimum allowed vapour fraction at the turbine outlet was 0.85 . The condenser cooling water inlet temperature was $20^{\circ} \mathrm{C}$ and the maximum allowed temperature rise for the cooling water was $15^{\circ} \mathrm{C}$.

e. The environment for the exergy analysis was considered to be $25^{\circ} \mathrm{C}\left(T_{o}\right)$ and 1 bar $\left(p_{o}\right)$. 
The rate of solar exergy incident on the receiver surface was calculated using the following equation [25]:

$$
\dot{E}_{s, r e c}=I_{s, b} A_{r e c}\left[1-\frac{4}{3} \frac{T_{o}}{T_{s}}+\frac{1}{3}\left(\frac{T_{o}}{T_{s}}\right)^{4}\right]
$$

Here, $I_{s, b}$ is the beam or direct solar irradiance on the receiver surface, $A_{\text {rec }}$ is the receiver surface area, $T_{o}$ is the environment temperature and $T_{s}$ is the temperature of the solar radiation. As mentioned, both the solar irradiance and the area in Eq. (2.1) are for the receiver surface, and not the collector surface. Therefore the exergy lost in collection between the collector and the receiver was not considered in this analysis. This is a reasonable assumption since the current study dealt with the comparison of power cycles for STPPs. As the solar field was assumed to be the same for both the KC and the SRC, the loss in collection would also be the same.

The rate of exergy destruction in the cycle was calculated for different components in the following ways. The relations below are mentioned for the $\mathrm{KC}$ with reference to Figure 2, but they were used in a similar manner for the SRC. For the condensers, the total rate of exergy destruction was calculated using the difference in the values of physical exergy across the condenser on the working fluid side. The difference in the physical exergies across the condenser on the working fluid side considered both the destroyed exergy and the exergy that was lost from the cycle with the cooling water; in other words, all the exergy that was removed from the working fluid because of destruction or loss to the environment. It is a valid approach since it was assumed that all the exergy taken away by the cooling water was not used for any other purpose, hence lost from the power cycle. Since the composition of the working fluid remains the same across the condenser, the chemical exergy need not be considered. The rate of exergy destruction across the condenser-1 (including the exergy lost by the power cycle with the cooling water) was calculated using Eq. (2.2). A similar relation was used for other condensers.

$$
\dot{E}_{d, c d 1}=\dot{m}_{5}\left[h_{5}-h_{6}-T_{o}\left(s_{5}-s_{6}\right)\right]
$$

The physical exergy rate at any state point was calculated using the following relation [26]:

$$
\dot{E}^{p h}=\dot{m}\left[h-h_{o}-T_{o}\left(s-s_{o}\right)\right]
$$

Here, $\dot{m}$ is the mass flow rate of the working fluid, $h$ and $s$ are respectively the specific enthalpy and specific entropy of the working fluid at the state point for which the physical exergy is calculated, and $h_{o}$ and $s_{o}$ are respectively the specific enthalpy and specific entropy of the working fluid at environment conditions.

For the receiver, the rate of exergy destruction was calculated as the difference in the values of physical exergy available in the solar radiation incident on the receiver surface and the exergy absorbed by the working fluid (which is, in turn, the difference in the values of physical exergy of the working fluid across the boiler). This value includes both the exergy that is destroyed during the transfer of heat from solar radiation to the working fluid, and the exergy that is lost to the environment due to the thermal losses in the receiver.

$$
\dot{E}_{d, \text { rec }}=\dot{E}_{s, \text { rec }}-\dot{m}_{17}\left[h_{1}-h_{17}-T_{o}\left(s_{1}-s_{17}\right)\right]
$$

For the remaining components, the rate of exergy destruction was calculated using the standard Gouy-Stodola relation [26]:

$$
\dot{E}_{d}=T_{o} \dot{S}_{g e n}
$$

The equations for the rate of exergy destruction for the different cycle components are shown in Table 1. 
Table 1: Rates of exergy destruction for different cycle components

\begin{tabular}{ll}
\hline Component & Rate of exergy destruction \\
\hline Turbine & $\dot{E}_{d, \text { tur }}=\dot{m}_{1} T_{o}\left(s_{2}-s_{1}\right)$ \\
Recuperator-1 & $\dot{E}_{d, \text { re1 }}=T_{o}\left[\dot{m}_{2}\left(s_{3}-s_{2}\right)+\dot{m}_{16}\left(s_{17}-s_{16}\right)\right]$ \\
Pump-1 & $\dot{E}_{d, p u 1}=\dot{m}_{6} T_{o}\left(s_{7}-s_{6}\right)$ \\
Separator & $\dot{E}_{d, s e p}=T_{o}\left[\dot{m}_{11} s_{11}+\dot{m}_{12} s_{12}-\dot{m}_{10} s_{10}\right]$ \\
Throttle valve & $\dot{E}_{d, t h v}=\dot{m}_{12} T_{o}\left(s_{13}-s_{12}\right)$ \\
Mixer-1 & $\dot{E}_{d, \text { mi1 }}=T_{o}\left[\dot{m}_{5} s_{5}-\dot{m}_{4} s_{4}-\dot{m}_{13} s_{13}\right]$ \\
Splitter & $\dot{E}_{d, s p l}=T_{o}\left[\dot{m}_{8} s_{8}+\dot{m}_{9} s_{9}-\dot{m}_{7} s_{7}\right]$ \\
\hline
\end{tabular}

For the recuperator-2, a relation similar to Eq. (2.7); for the pump-2, a relation similar to Eq. (2.8); and for the mixer-2, a relation similar to Eq. (2.11) were used to calculate the respective rates of exergy destruction.

\section{Results}

The radiation emitted by the sun can be approximated as blackbody with a temperature of $5800 \mathrm{~K}$ [27]. Thus, using Eq. (2.1) with $I_{s, b}=0.65 \mathrm{MW} / \mathrm{m}^{2}, A_{\text {rec }}=42.65 \mathrm{~m}^{2}, T_{\mathrm{s}}=5800 \mathrm{~K}$ and $T_{o}=298.15 \mathrm{~K}$, the exergy available in incident solar radiation on the receiver surface was calculated as $25.80 \mathrm{MW}$. Both the SRC and the KC were simulated for turbine inlet pressures increasing at an interval of 10 bar between 100 bar and 160 bar. The operation of the SRC was however limited to a maximum turbine inlet pressure of 114 bar because of the turbine outlet vapour quality constraint $(\geq 0.85)$. For the KC, a maximum turbine inlet pressure of 160 bar was achievable without violating the turbine outlet vapour fraction constraint.

The best performing SRC operated with a turbine inlet pressure of 114 bar (with a plant exergy efficiency of $30.29 \%$ ) and therefore this case was selected for comparison with the performance of the KC. Figure 4 shows the variation in plant exergy efficiency for the KC at different turbine inlet pressures (between 100 and 160 bar) and turbine inlet ammonia mass fractions (between 0.5 and 0.9 ). Figure 4 might suggest to the reader that using pure ammonia as the working fluid would result in obtaining the highest plant exergy efficiency. However, as observed by Knudsen [15] and as mentioned by Rodríguez et al. [28], the efficiency shows a drop in the value when pure ammonia is used until its critical pressure (about 113.5 bar). For the pressure range considered in this study which is mostly supercritical for pure ammonia, it is not recommended to be used in supercritical Rankine cycles [29], and therefore not evaluated here.

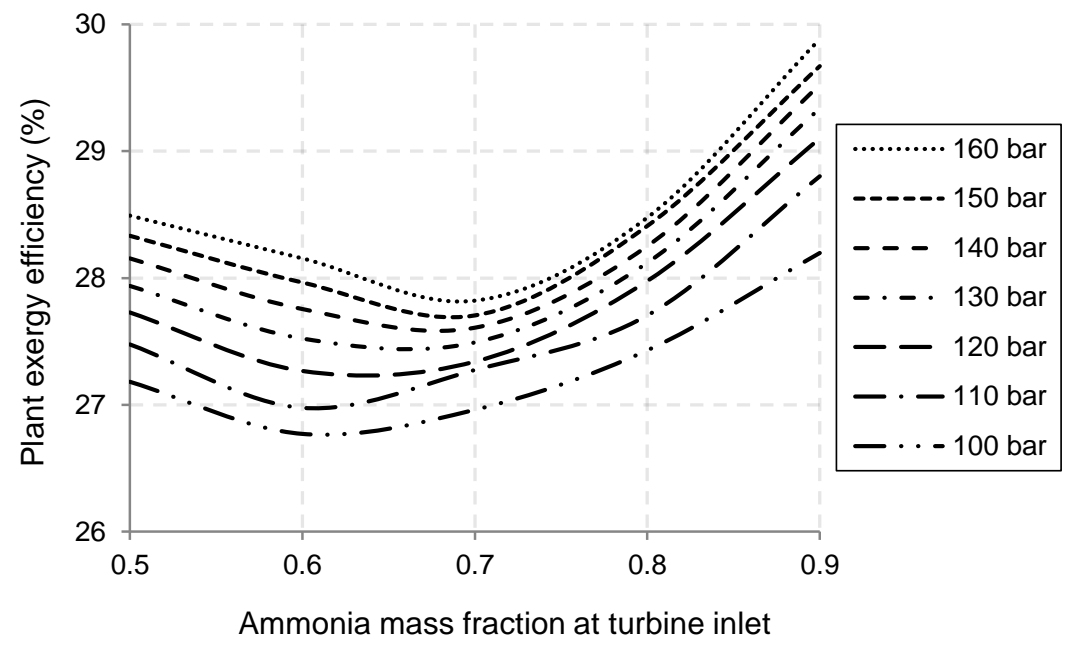


Figure 4: Plant exergy efficiencies for the KC for different ammonia mass fractions and pressures at turbine inlet

Comparing the exergy efficiencies for the KC and the SRC for operation with heat input solely from the solar receiver, it may be observed that the exergy efficiency of the KC with the best performance (29.88\% with an ammonia mass fraction of 0.9 and a pressure of 160 bar at the turbine inlet) is slightly less than that of the SRC operating with a turbine inlet pressure of 114 bar (30.29\%). Thus, from the plant exergy efficiency perspective, the SRC should be the preferred cycle of operation for an STPP with heat input from only solar receiver. However, even in this operation mode (i.e. without storage), there are other benefits of using ammonia-water mixtures as the cycle working fluid. The volume flow rate of the working fluid at the turbine outlet is much lower for the KC than the SRC (at the most $14.29 \mathrm{~m}^{3} / \mathrm{s}$ for the KC with an ammonia mass fraction of 0.5 and a pressure of 100 bar at the turbine inlet as compared with $161.15 \mathrm{~m}^{3} / \mathrm{s}$ for the SRC with a turbine inlet pressure of 114 bar). It means that the KC can operate at much higher turbine inlet pressures with a more compact turbine without violating the minimum vapour fraction condition at the turbine outlet. This implies a reduction in the turbine cost for the KC for a similar work output as the SRC.

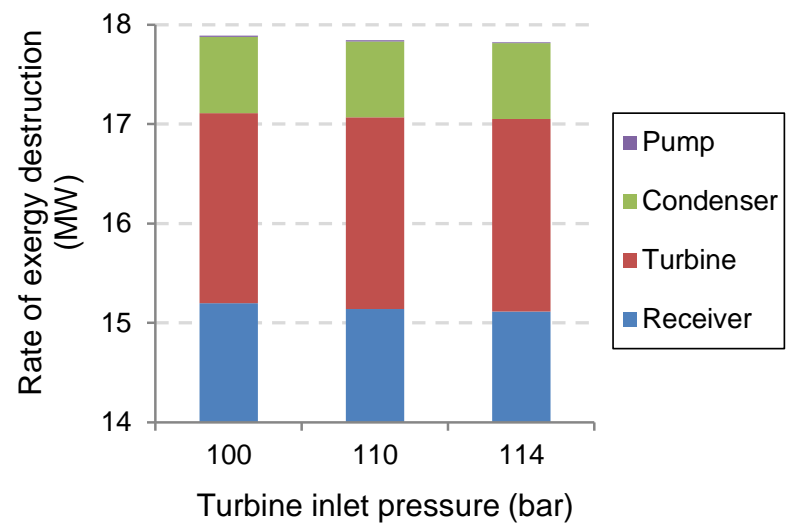

Figure 5: Rate of exergy destruction for different components of the SRC at different turbine inlet pressures

Figure 5 shows the rate of exergy destruction for different components of the SRC for different pressures at the turbine inlet, while Figure 6 shows the same for the $\mathrm{KC}$ for different ammonia mass fractions and pressures at the turbine inlet. 


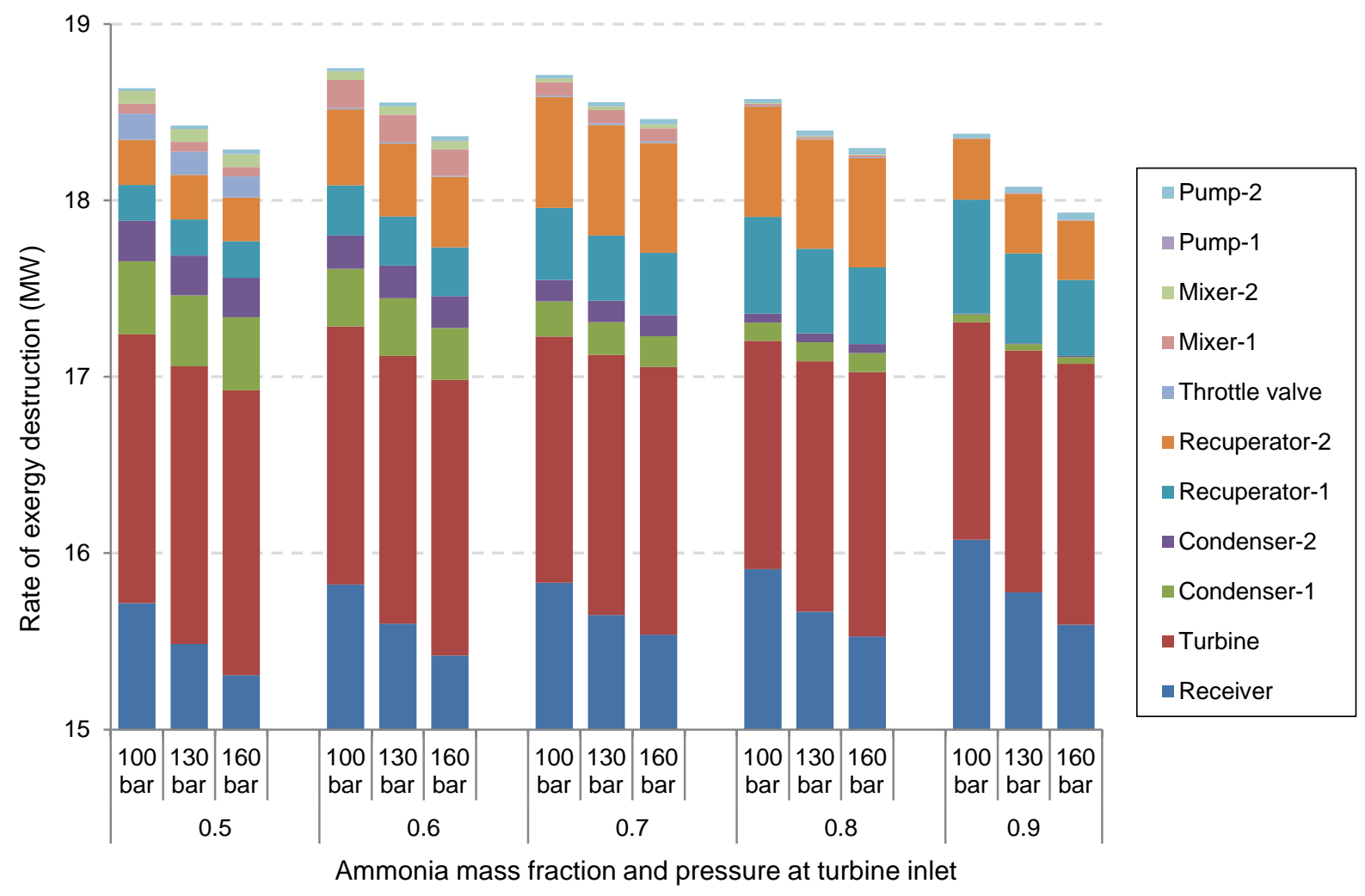

Figure 6: Rate of exergy destruction for different components of the KC for different ammonia mass fractions and pressures at turbine inlet

From Figure 5, it may be observed that for the SRC, the major portion of the incident solar exergy is destroyed or lost in the receiver. The turbine shows the second highest rate of exergy destruction, followed by the condenser and the pump. The rate of exergy destruction in the pump increases with the increasing value of pressure at the turbine inlet, however, it is still negligible for all the cases. From Figure 6, it may be observed that similar to the SRC, the major portion of the incident solar exergy for the KC is also destroyed or lost in the receiver.

An important aspect of an STPP is the thermal energy storage system. It is essential for an uninterrupted operation of the plant, and increases the sustainability of solar thermal electricity technology [30]. For the SRC operating with a turbine inlet pressure of $114 \mathrm{bar}$, Figure 7 shows temperature vs. heat transfer (T - $\dot{Q}$ ) diagram for the storage heat exchanger. It may be observed that the molten-salt cannot be operated below a cold temperature of $270{ }^{\circ} \mathrm{C}$ for the SRC without violating the pinch point criterion. For the SRC, a molten-salt mass flow rate of $93.28 \mathrm{~kg} / \mathrm{s}$ was required for operation from storage. Similarly for the KC, a molten-salt mass flow rate of $61.03 \mathrm{~kg} / \mathrm{s}$ and $62.19 \mathrm{~kg} / \mathrm{s}$ was required at a turbine inlet ammonia mass fraction and pressure of 0.9 and $160 \mathrm{bar}$, and 0.5 and $100 \mathrm{bar}$, respectively. The required molten-salt mass flow rates for all the other cases for the KC, i.e., between $0.5 / 100$ bar and $0.9 / 160$ bar, were between these two values.

Figure 8 shows the $\mathrm{T}$ - $\dot{\mathrm{Q}}$ diagram for the KC operating with a turbine inlet ammonia mass fraction of 0.5 at different turbine inlet pressures. It may be observed that the molten-salt can be used for a much wider range of storage temperature difference with an ammonia-water mixture as the working fluid because of the better match between the hot and the cold temperature curves. Similar observations were made for all the turbine inlet ammonia mass fractions. 


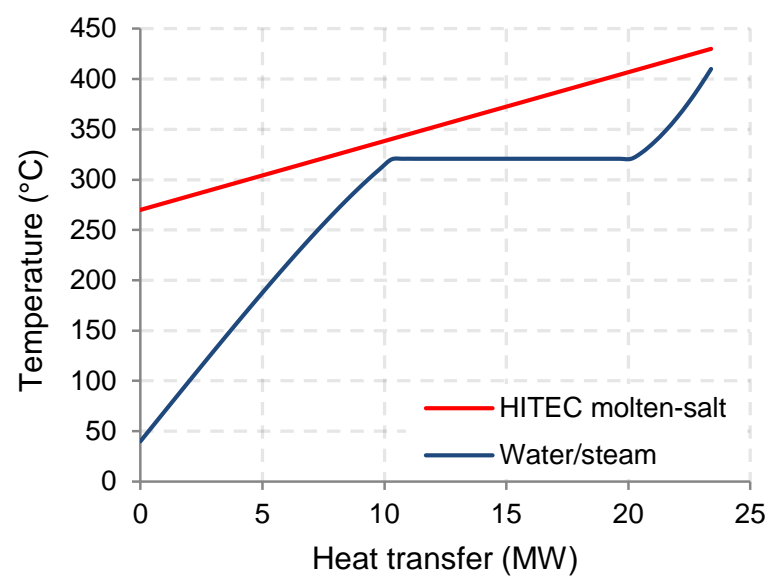

Figure 7: T - $\dot{Q}$ diagram for the SRC operating with a turbine inlet pressure of 114 bar

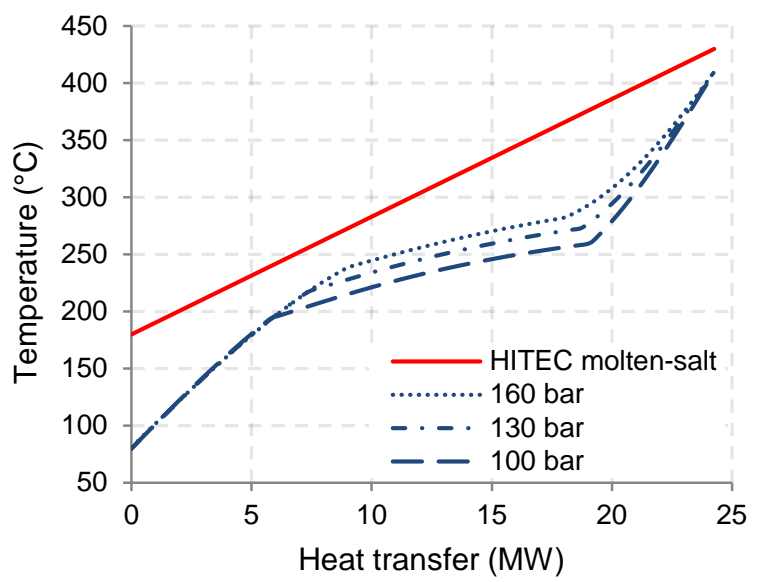

Figure 8: $\mathrm{T}$ - $\dot{Q}$ diagram for the KC operating with a turbine inlet ammonia mass fraction of 0.5 at different turbine inlet pressures

On comparing Figure 7 and Figure 8, it may be noticed that there is a slight difference in the value of heat input for the SRC and the KC. This is because two different property calculation methods were used in the two parts of this analysis (i.e. PR-BM for power cycle optimisation and REFPROP for analysis of operation from storage); however, this does not compromise the results of this part of the analysis as the comparison is made with respect to the storage mass flow rate and size, and not for re-optimising the cycle for operation from storage.

\section{Discussion}

From Figure 4, it may be observed that with an increasing ammonia mass fraction at the turbine inlet, the plant exergy efficiency first decreases, reaches a minimum value and then begins to increase again. When comparing this trend with some other studies for medium or high temperature KC (see, e.g., [7,13]), it is different in a sense that some of the previous studies showed an optimum value of the turbine inlet ammonia mass fraction for maximum exergy efficiency, for a given turbine inlet pressure. The current trend could be because of the difference in the cycle layout, i.e., the amount of recuperation and the placement of the recuperators. For instance, the recuperator-1 (generally not considered in previous studies) is useful for cycle configurations with high turbine inlet ammonia mass fraction as the temperature at the turbine outlet is quite high in these cases. At the same time, it would be beneficial to have another recuperator transferring the heat from stream 11 to stream 16 (in Figure 2) for cycle configurations with lower values of turbine inlet ammonia mass fraction so as to decrease the rate of exergy destruction in the mixer-2 by having a better temperature match between the mixing streams. This behaviour suggests that different cycle layouts could provide different, or no optimum values of 
turbine inlet ammonia mass fractions from exergy efficiency perspective. For all the components in the KC, the rate of exergy destruction decreases with increasing turbine inlet pressure. However, different components exhibit different behaviour with the changing ammonia mass fraction at the turbine inlet. With increasing value of the turbine inlet ammonia mass fraction, the rate of exergy destruction in the two condensers, the recuperator1 and the turbine shows a decreasing trend; whereas the rate of exergy destruction in the recuperator- 2 first increases and then decreases, depending on the pinch criterion satisfaction and the match between the inlet and the outlet stream temperature profiles. This pattern, combined with the fact that the rate of exergy destruction in the throttle valve and the mixers becomes negligible at higher values of turbine inlet ammonia mass fractions due to a better match in the mixing streams' temperatures, causes the exergy efficiency to increase again after reaching the minimum.

The rate of exergy destruction in the condensers is smaller for the KC than the SRC because the condensation takes place with a temperature glide for the KC. However, this benefit for the KC comes with a drawback of having higher turbine outlet pressures and temperatures for feasible cycle operation. The rate of exergy destruction in the turbine is also smaller for the KC, though only by a small margin. The rate of exergy destruction in the receiver for the KC is higher than that for the SRC for all the combinations of ammonia mass fractions and pressures at the turbine inlet. For the KC, the rate of exergy destruction in the receiver increases with the increase in the turbine inlet ammonia mass fraction, but decreases with the increase in the turbine inlet pressure. It is because the bubble point for the ammonia-water mixture decreases with increasing ammonia mass fraction (when the pressure is kept constant), thereby worsening the match between the temperature of the heat supply and the ammonia-water mixture temperature profile resulting in a higher amount of destroyed exergy. On the other hand, the bubble point of the ammonia-water mixture increases with the increasing value of the turbine inlet pressure (when the ammonia mass fraction at the turbine inlet is kept constant), resulting in a decreasing rate of exergy destruction. In addition, as also highlighted by Kim et al. [31], the curvature of the temperature profile of the ammonia-water mixture changes its convexity with changing ammonia mass fraction. This behaviour results in an increasing rate of exergy destruction in the receiver as the ammonia mass fraction increases. It then depends on the rest of the power cycle to compensate for the increasing losses in the receiver, to show an overall benefit or loss with changing ammonia mass fraction.

Since it is assumed that there is no heat loss or pressure drop in the separator and the splitter for the KC, the rate of exergy destruction in these components is zero, as they simply divide the incoming mass flow rate and the working fluid composition to different values in the outgoing streams. Therefore, the separator and the splitter used in the KC are not included in Figure 6.

As the molten-salt mass flow rate for the KC was found to be about $33 \%$ smaller than that for the SRC, a less amount of salt is required by the KC for a day's operation than the SRC. The less molten-salt flow rate results in reduced pumping power and piping requirements, making the $\mathrm{KC}$ an economically better alternative than the SRC when operating from storage. It also makes it possible to use a simple sensible heat storage system instead of the one proposed for DSG operation which is both expensive and complex [3]. The operation from storage was analysed once the design point of the power cycle was determined, and then the cycle was assumed to operate always at that design point. However, in practice, there will be instances when the cycle is being operated in off-design conditions resulting in a lower turbine inlet temperature or pressure (if the cycle is operating in sliding pressure mode). Future work will include an off-design analysis to assess the potential benefits of the KC for an STPP with DSG in such conditions.

From a cost perspective, Kalina and Tribus [32] reported that most of the vendors did not ask for an increased price for different components because of the presence of ammonia, and it's only the boiler and the turbine where the temperature and the pressure are high enough to take extra precautions in terms of the materials used. This combined with the fact that a relatively smaller turbine is required because of a much smaller volumetric flow rate and the possibility to use a simpler storage system with reduced size for about the same power output makes the KC economically attractive. On the other hand, the cost of additional equipment like recuperators, separator, mixers and splitters should be compensated by the reduction in the cost from the turbine and the 
storage system. A more detailed cost study of the KC for geothermal power applications can be found in Campos Rodríguez et al. [9] and for waste heat recovery application in Larsen et al. [33].

\section{Conclusion}

The KC was modelled as the power cycle for an STPP operating with DSG. The performance of the cycle was analysed using exergy analysis while keeping the heat input to the cycle as constant, and varying the pressure and the ammonia mass fraction at the turbine inlet. The performances of a KC and an SRC were also compared. When operating with heat input solely from the solar receiver, the SRC shows a slightly better exergy efficiency than the most promising KC configuration. However, considering that the volume flow rate at the turbine outlet is significantly lower for the KC than the SRC and that the vapour fraction at the turbine outlet is not a limiting factor for the $\mathrm{KC}$, it allows the $\mathrm{KC}$ to be operated at much higher turbine inlet pressures while using more compact turbines. This difference is economically significant. The exergy analysis of the two cycles provides the rates of exergy destruction in various components of the different cycles. The KC experiences a higher rate of exergy destruction in the receiver when operated with heat input solely from the solar receiver, while the SRC shows a higher rate of exergy destruction in the turbine and the condenser. Other components in the KC exhibit a varying behaviour with respect to the rate of exergy destruction depending on the ammonia mass fraction and pressure at the turbine inlet. The trend of the exergy efficiency with varying turbine inlet ammonia mass fraction depends on the amount of recuperation and the placement of the recuperators.

With a two-tank molten-salt storage system as the primary source of heat input, the KC shows a clear advantage over the SRC by utilising a wider temperature range, thus reducing the storage size by about $33 \%$ for approximately the same power output. Using the KC also makes it possible to employ a simple sensible storage system instead of the complex storage system generally proposed for DSG operation.

\section{Nomenclature}

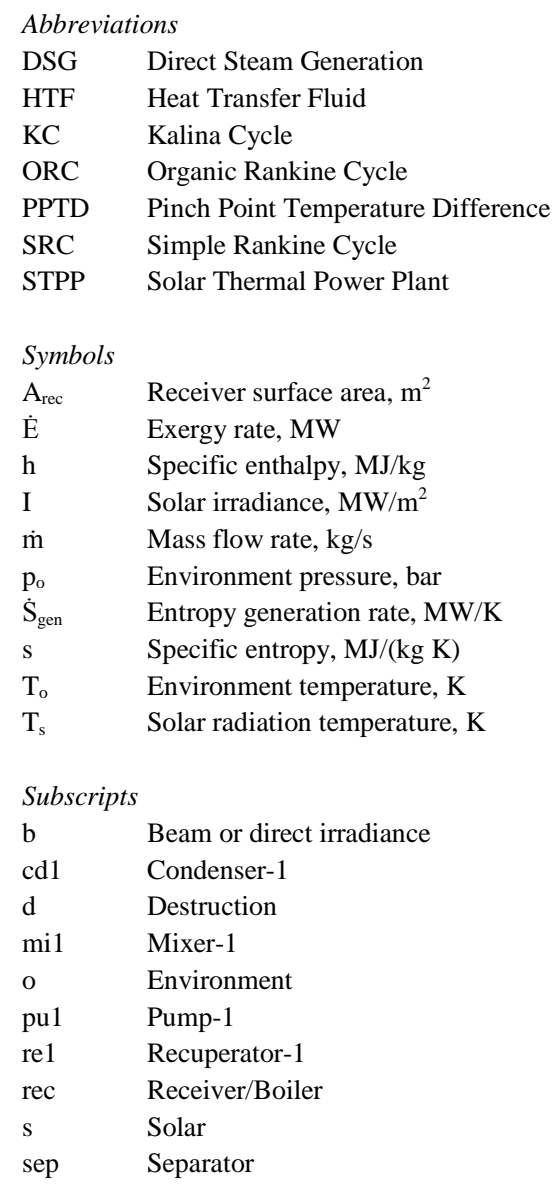




$\begin{array}{ll}\text { spl } & \text { Splitter } \\ \text { thv } & \text { Throttle valve } \\ \text { tur } & \text { Turbine }\end{array}$

Superscripts

ph Physical exergy

\section{References}

[1] Greenpeace International, SolarPACES, and ESTELA, 2009, Concentrating Solar Power: Global Outlook 2009, Amsterdam, The Netherlands.

[2] Zarza E., Valenzuela L., León J., Hennecke K., Eck M., Weyers H.-D., and Eickhoff M., 2004, “Direct steam generation in parabolic troughs: Final results and conclusions of the DISS project,” Energy, 29(5-6), pp. 635-644.

[3] Laing D., Bahl C., Bauer T., Lehmann D., and Steinmann W.-D., 2011, “Thermal energy storage for direct steam generation,” Sol. Energy, 85(4), pp. 627-633.

[4] Chen H., Goswami D. Y., Rahman M. M., and Stefanakos E. K., 2011, “A supercritical Rankine cycle using zeotropic mixture working fluids for the conversion of low-grade heat into power,” Energy, 36(1), pp. 549-555.

[5] Mirolli M. D., 2012, “Kalina cycle power systems in waste heat recovery applications,” pp. 1-8 [Online]. Available: www.globalcement.com/magazine/articles/721-kalina-cycle-power-systems-in-waste-heat-recovery-applications. [Accessed: 30Aug-2013].

[6] Kalina A. I., 2002, Method of preventing nitridation or carburization of metals, United States Patent 6482272 B2.

[7] Bombarda P., Invernizzi C. M., and Pietra C., 2010, "Heat recovery from Diesel engines: A thermodynamic comparison between Kalina and ORC cycles,” Appl. Therm. Eng., 30(2-3), pp. 212-219.

[8] Singh O. K., and Kaushik S. C., 2013, "Energy and exergy analysis and optimization of Kalina cycle coupled with a coal fired steam power plant,” Appl. Therm. Eng., 51(1-2), pp. 787-800.

[9] Campos Rodríguez C. E., Escobar Palacio J. C., Venturini O. J., Silva Lora E. E., Cobas V. M., Marques dos Santos D., Lofrano Dotto F. R., and Gialluca V., 2013, "Exergetic and economic comparison of ORC and Kalina cycle for low temperature enhanced geothermal system in Brazil,” Appl. Therm. Eng., 52(1), pp. 109-119.

[10] Wang J., Yan Z., Zhou E., and Dai Y., 2013, "Parametric analysis and optimization of a Kalina cycle driven by solar energy,” Appl. Therm. Eng., 50(1), pp. 408-415.

[11] Coskun A., Bolatturk A., and Kanoglu M., 2014, “Thermodynamic and economic analysis and optimization of power cycles for a medium temperature geothermal resource,” Energy Convers. Manag., 78, pp. 39-49.

[12] Ibrahim M. B., and Kovach R. M., 1993, “A Kalina cycle application for power generation,” Energy, 18(9), pp. 961-969.

[13] Nag P. K., and Gupta A. V. S. S. K. S., 1998, “Exergy analysis of the Kalina cycle,” Appl. Therm. Eng., 18(6), pp. 427-439.

[14] Dejfors C., Thorin E., and Svedberg G., 1998, “Ammonia-water power cycles for direct-fired cogeneration applications,” Energy Convers. Manag., 39(16-18), pp. 1675-1681.

[15] Knudsen T., Clausen L. R., Haglind F., and Modi A., 2013, "Energy and exergy analysis of the Kalina cycle for use in concentrated solar power plants with direct steam generation,” Presented at the ISES Solar World Congress 2013. November 3-7, 2013. Cancun, Mexico. To be published in Energy Procedia (Elsevier).

[16] Modi A., Knudsen T., Haglind F., and Clausen L. R., 2013, "Feasibility of using ammonia-water mixture in high temperature concentrated solar power plants with direct vapour generation,” Presented at the ISES Solar World Congress 2013. November 3-7, 2013. Cancun, Mexico. To be published in Energy Procedia (Elsevier).

[17] Xu C., Wang Z., Li X., and Sun F., 2011, “Energy and exergy analysis of solar power tower plants,” Appl. Therm. Eng., 31(1718), pp. 3904-3913.

[18] Zhang X., He M., and Zhang Y., 2012, “A review of research on the Kalina cycle,” Renew. Sustain. Energy Rev., 16(7), pp. 5309-5318.

[19] AspenTech, 2013, “Aspen Plus” [Online]. Available: www.aspentech.com/products/aspen-plus.aspx. [Accessed: 30-Aug-2013].

[20] Mathias P. M., Boston J. F., and Watanasiri S., 1984, "Effective utilization of equations of state for thermodynamic properties in process simulation,” AIChE J., 30(2), pp. 182-186.

[21] Coastal Chemical Company, 2013, “HITEC Heat Transfer Salt” [Online]. Available: www.coal2nuclear.com/MSR - HITEC Heat Transfer Salt.pdf. [Accessed: 30-Aug-2013].

[22] National Institute for Standards and Technology, 2013, "REFPROP MATLAB Interface” [Online]. Available: www.boulder.nist.gov/div838/theory/refprop/Frequently_asked_questions.htm\#MatLabApplications. [Accessed: 30-Aug-2013].

[23] NREL, 2013, "Power tower projects” [Online]. Available: www.nrel.gov/csp/solarpaces/power_tower.cfm. [Accessed: 30-Aug2013].

[24] SOLUCAR, 2006, "PS10: a 11.0-MWe Solar Tower Power Plant with Saturated Steam Receiver" [Online]. Available: www.upcomillas.es/catedras/crm/report05/Comunicaciones/Mesa IV/D. Valerio Fern\%25C3\%25A1ndez - Solucar 2.pdf. [Accessed: 30-Aug-2013].

[25] Petela R., 2003, “Exergy of undiluted thermal radiation,” Sol. Energy, 74(6), pp. 469-488.

[26] Dincer I., and Rosen M. A., 2013, Exergy, Elsevier Ltd., Oxford, UK.

[27] Bergman T. L., Lavine A. S., Incropera F. P., and Dewitt D. P., 2011, Fundamentals of heat and mass transfer, John Wiley \& Sons, Inc., Jefferson City, USA.

[28] Rodríguez C. E. C., Palacio J. C. E., Sotomonte C. R., Leme M., Venturini O. J., Lora E. E. S., Cobas V. M., dos Santos D. M., Dotto F. R. L., and Giallucca V., 2012, "Exergetic and economic analysis of Kalina cycle for low temperature geothermal sources 
in Brazil,” Proceedings of ECOS 2012 - The 25th International Conference on Efficiency, Cost, Optimization, Simulation and Environment Impact of Energy Systems, Perugia, Italy, pp. 345-1.

[29] Chen H., Goswami D. Y., and Stefanakos E. K., 2010, "A review of thermodynamic cycles and working fluids for the conversion of low-grade heat,” Renew. Sustain. Energy Rev., 14(9), pp. 3059-3067.

[30] Adinberg R., 2011, "Simulation analysis of thermal storage for concentrating solar power,” Appl. Therm. Eng., 31(16), pp. 35883594.

[31] Kim K. H., Han C. H., and Kim K., 2012, "Effects of ammonia concentration on the thermodynamic performances of ammoniawater based power cycles,” Thermochim. Acta, 530, pp. 7-16.

[32] Kalina A. I., and Tribus M., 1989, “The Kalina power cycles, A progress report,” Proceedings of the American Power Conference, Illinois Institute of Technology, Chicago, Illinois, pp. 5-21.

[33] Larsen U., Nguyen T.-V., Knudsen T., and Haglind F., 2014, "System analysis and optimisation of a Kalina split-cycle for waste heat recovery on large marine diesel engines,” Energy, 64, pp. 484-494. 